\title{
Avaliação sistêmica da potencialidade de aplicativos (softwares) no ensino da expressão gráfica utilizando mapas conceituais.
}

Avaliação sistêmica da potencialidade de softwares no ensino de expressão gráfica utilizando mapas conceituais

OURIVES, Eliete Auxiliadora Assunção; Pós-doutorado; UFSC

elieteourives@gmail.com

FIGUEIREDO, Luiz Fernando Gonçalves de; Pós-doutorado; UFSC

Iffigueiredo2009@gmail.com

VIEIRA, Milton Luiz Horn; Pós-doutorado; UFSC

Milton@cce.ufsc.br

ANDRADE, William Machado de; Doutorado; UFSC

William.ufsc.@gmail.com

NISHIDA, Jonathan Ken; Doutorando; UFSC

jounishida@gmail.com

PEIXOTO, Vírgilio Vieira; Mestre; UFSC

virgilio@cce.ufsc.br

FIGUEIREDO, Attilio Bolivar; Graduando; UFSC

Gastronomia.cosine@hotmail.com

\section{Resumo}

A informática no ensino é realidade vivenciada por grande parte dos professores e alunos tanto no ensino fundamental e médio como no ensino superior. Porém, o uso de aplicativos softwares não é suficiente para assegurar melhorias no ensino se não for observada a qualidade dele, pois ele em si, não provoca nenhuma mudança no processo educacional se não for utilizado dentro de um contexto que envolva um projeto pedagógico com o planejamento do conteúdo programático. 0 mapa conceitual é uma ferramenta de estruturação muito utilizada no ensino e com grande sucesso. Assim, este trabalho de caráter exploratório e descritivo, usando a experiência vivenciada em sala de aula, e o mapa conceitual como ferramenta fundamental de estruturação e análise, tem como objetivo, analisar alguns aplicativos softwares de uso profissional no ensino da modelagem 2D e 3D.

Palavras Chave: ensino; modelagem 2D e 3D; mapas conceituais.

\footnotetext{
Abstract

Informatics in education is a reality experienced by a large part of teachers and students in elementary and secondary education as well as in higher education. However, the use of software applications is not sufficient to ensure improvements in teaching if the quality of the software is not
} 
observed, since it does not in itself cause any change in the educational process if it is not used within a context that involves a pedagogical project with the content planning. The conceptual map is a structuring tool widely used in teaching and with great success. Thus, this work of exploratory and descriptive character, using the experience lived in the classroom, and the conceptual map as a fundamental tool of structuring and analysis, aims to analyze some software applications for professional use in teaching 2D and 3D modeling.

Keywords: teaching; 2D and 3D modeling; conceptual maps.

\title{
1 Introdução
}

A educação é um processo de descoberta, exploração e de observação, além de eterna construção do conhecimento. Muitas coisas que até pouco tempo atrás eram sonhos, atualmente, com os avanços tecnológicos existentes tornaram-se realidade na área da educação Moran 2000. E, diante de novos paradigmas, estamos reaprendendo a conhecer, a comunicar-nos, a ensinar e a aprender; a integrar o humano e o tecnológico; a integrar o individual, grupal e o social.

Para Moran (2000),

\begin{abstract}
“Educar é colaborar para que professores e alunos nas escolas e organizações transformem suas vidas em processos permanentes de aprendizagem... Uma mudança qualitativa no processo de ensino/aprendizagem acontece quando conseguimos integrar dentro de uma visão inovadora todas as tecnologias: as telemáticas, as audiovisuais, as textuais, as orais, musicais, lúdicas e corporais... É importante diversificar as formas de dar aula, de realizar atividades, de avaliar"(MORAN, 2000, 137p).
\end{abstract}

Passamos muito rapidamente do livro para a televisão e vídeo e destes para o Computador e a Internet, sem aprender e explorar todas as possibilidades de cada meio.

Segundo Bastos e colaboradores (2005) a Educação, no escopo da Ciência e a Tecnologia, tem um lugar de destaque nas transformações da sociedade e na formação do sujeito que atua nessa sociedade. Para os autores a adesão a essas tecnologias não deve acontecer de forma incondicional como se fossem solucionar todos os problemas da educação necessita explorar as potencialidades desses recursos nas situações de ensino-aprendizagem e evitar o uso indiscriminado da tecnologia apenas por suas virtualidades técnicas, se esquecendo das virtudes pedagógicas.

De acordo com Barcelos (2004), da mesma forma que em outros setores na educação escolar, a tecnologia melhora e permite mostrar os resultados de tal melhoria. Nesse processo incluem não só mudanças curriculares como também a introdução de novos processos de ensino e aprendizagem, de produtos, materiais, ideias e pessoas, assim como, a discussão e análise sobre o uso de aplicativos softwares no ensino. Para Braga (2001), o uso de tecnologias permite à interatividade, a participação, a intervenção, a bidirecionalidade e a multidisciplicinaridade, maximizando a sensorialidade e rompendo com a linearidade e também com a separação emissor/receptor. Sendo que a interatividade é um princípio do mundo digital e da cibercultura, isto é, do ambiente de comunicação baseado na tecnologia e inovação, (internet, site, game e software). É o modo de comunicação que desafiou e ainda desafia professores e gestores da educação, igualmente centrados no paradigma da transmissão, a buscar a construção da sala de aula onde a aprendizagem se dá com a participação e cooperação dos alunos (SILVA, 2000). 
Segundo Mercado (1998), ao professor cabe o papel de estar engajado no processo consciente das reais capacidades da tecnologia, do seu potencial e de suas limitações, para selecionar a melhor utilização a ser explorada num determinado conteúdo. Diante disso, é importante saber explorar estrategicamente as tecnologias disponíveis (internet, site, game, softwares, etc) e transformá-la num poderoso instrumento a serviço de todos que buscam a evolução da educação. Assim, formando o tema para a proposta deste trabalho, no sentido de apresentar ao professor estratégias de como analisar qualitativamente um aplicativo software a ser utilizado em uma disciplina de modelagem 2D e 3D, na área de expressão gráfica, que geralmente é oferecida aos cursos de arquitetura, engenharia e design.

\section{Informática no ensino.}

O projeto assistido por computador, do inglês, Computer Aided Design (CAD) é uma tecnologia na informática baseada em computadores, que é utilizada por engenheiros arquitetos, design, e outros profissionais para executar os seus projetos. Entre os aplicativos atuais de CAD estão programas de desenho bidimensional, de modelagem de superfícies (NURBS), de modelagem tridimensional (paramétricas e diretas), e de modelagem de informações de construção (BIM), sendo esta, uma tecnologia baseada em modelos ligados a uma base de dados com informações sobre o projeto. Embora, o uso do CAD para criar desenhos bidimensionais continue popular, o potencial do $C A D$, atualmente, vai além da mera capacidade de fazer desenhos. Os programas de CAD baseados em modelos orientados a objeto oferecem aos projetistas, engenheiros, arquitetos, designers, etc., a oportunidade de capturar digitalmente a definição de um produto e integrar essa definição a base de informações da empresa. (LEAKE, J., M. et al)

Entretanto, independentemente do aplicativo utilizado, e da sua capacidade, a informática no ensino deve ser vista como meio instrucional, já dizia Rocha \& Campos (1993), sendo o professor um dos atores indispensável, e que o mesmo tem a sua função ampliada com o seu uso, como por exemplo, tempo maior para contato com o aluno, e com isso, valorizando a aprendizagem por descoberta, e também fundamentada em teorias para poder destacar o processo de construção de conhecimento pelo aluno.

Outro fator relevante, é que o uso da informática não é suficiente para assegurar melhorias no ensino se não for observada a qualidade do aplicativo software utilizado, pois ele em si não provoca nenhuma mudança no processo educacional se não for utilizado dentro de um contexto que envolva um projeto pedagógico. $O$ aplicativo software tem que ser visto como um instrumento que facilite "o fazer" no ambiente educacional, apresentando algumas características fundamentais para a sua aplicabilidade e usabilidade, e consequentemente, proporcionar melhor desempenho no processo de aprendizagem do conteúdo programático da disciplina ou tema educacional. (CANTARELLI, 2017).

A necessidade de inserir mecanismos de apoio à aprendizagem, tais como estratégias e táticas de ensino, baseadas naquelas utilizadas pelos professores em sala de aula, é um dos grandes desafios na pesquisa desta área. As limitações de hardware e software são fatores que contribuem para que esta tarefa não seja atingida ainda na sua plenitude (GOULART \& GIRAFFA, 2001). Giraffa $(1999$, p.1) coloca que: "Todo programa pode ser considerado um programa educacional desde que utilize uma metodologia que o contextualize no processo ensino-aprendizagem." Assim, qualquer software pode ser utilizado no processo educacional, dependendo da criatividade de seus usuários.

Segundo Cantarelli (2017) para verificar se o software possui características que assegurem 
o sucesso no âmbito educacional é necessário avaliar a interface, o conteúdo, o grau de interatividade, a estratégia utilizada, a motivação, o controle por parte do usuário e a mídia utilizada.

E que, para avaliarmos um aplicativo software destinado ao ensino, para Catarelli (2017), é importante estabelecer parâmetros mínimos de avaliação para as características, que formam um conjunto de atributos que evidenciam a conveniência e a viabilidade da utilização do aplicativo software em situações educacionais, como:

Ambiente educacional: o software deve permitir a identificação do ambiente educacional e do modelo de aprendizagem que privilegia.

Pertinência em relação ao programa da disciplina: o software deve ser adequado e pertinente em relação à disciplina especifica.

Aspetos didáticos: o software deve contribuir para que o aluno alcance o objetivo educacional. E importante que inclua atributos como: clareza, correção dos conteúdos, recursos para motivação, carga informacional e tratamento de erros.

Dessa forma, com base nos conceitos de Cantarelli (2017), que a proposta deste trabalho é contribuir avaliando qualitativamente, alguns softwares, geralmente utilizados no meio educacional na área de expressão gráfica, em disciplinas de modelagem 2D e 3D, comumente oferecidos para os cursos de arquitetura, engenharia e design. E, assim o professor poder verificar, com base nos critérios de avaliação proposto neste trabalho, se o aplicativo software avaliado oferece mais potencialidade em termos de apoio ao tipo de representação gráfica e sua aplicação (orgânica, mecânico, mobiliário, topografia e arquitetônico). É importante mencionar que outros critérios podem ser adaptados ou inseridos no processo de avaliação qualitativa proposto nesta pesquisa. A seguir, será apresentado os mapas conceituais, conceitos e aplicações, destacando que foi a ferramenta usada por melhorar a compreensão dos diferentes objetivos e tornar possível aprender para sistematizar as ações coordenadas em sala de aula.

\section{Os mapas conceituais: ferramenta importante na construção da informação e conhecimento no ensino}

O pesquisador norte-americano Joseph Novak, é considerado o criador da teoria dos mapas conceituais, que foi baseado na teoria da aprendizagem significativa construtivista de David Ausubel conforme Novak (1977). Segundo Bax \& Souza (2008), nesta teoria o indivíduo constrói o seu conhecimento e significado, que facilita o aprendizado do conteúdo sistematizado em conteúdo significativo. Esses mapas podem ser aplicados de modo individual ou em grupo para qualquer tipo de assunto.

A estratégia de Novak (1977), criada a partir dos princípios da teoria de Ausubel (1968), organizou os mapas para serem utilizados no processo de ensino e se baseia na: diferenciação progressiva (relação entre proposições e conceitos, semelhanças e diferenças), onde as ideias mais gerais e inclusivas são apresentadas no início do mapa para depois serem diferenciadas; e reconciliação integrativa (cada nova informação permite o deslocamento das hierarquias conceituais evidenciando as relações de subordinação e ordenação entre os conceitos), e exploramse as relações entre proposições (palavra(s) que ligam) e conceitos.

De acordo com Guerra (1983) e Bax \& Souza (2008), mapas conceituais são diagramas - 
elaborados a partir de uma lista de ideias armazenadas na memória - que indicam relações entre conceitos de um conteúdo/tema/assunto de uma disciplina ou unidade de ensino, ou como instrumento de avaliação. Podem indicar também proposições entre dois conceitos ligados por uma unidade semântica. E, permite: organizar o conhecimento, aumentando a eficiência da aprendizagem; organizar hierarquicamente os conteúdos das diferentes disciplinas; e identificar a estrutura de um artigo, texto, conteúdo auxiliando a compreensão do aluno.

Nesses mapas, os conceitos mais abrangentes ou gerais são colocados no topo. À medida que se desce são encontrados conceitos intermediários, que são subordinados e conectados através de uma ligação semântica. A seguir será abordado sobre as etapas do método utilizado para aplicar os mapas mentais e conceituais no ensino da expressão gráfica no curso de design.

\section{Proposta de avaliação de potencialidade de aplicativos (softwares) no ensino da expressão gráfica}

\subsection{Introdução}

A pesquisa começou através da construção dos mapas conceituais. Foram construídos quatro mapas conceituais, abordando temas importantes a serem considerados no âmbito educacional:

Mapa conceitual 1 - mapa conceitual para determinar como proceder em atividade acadêmica;

Mapa conceitual 2 - mapa conceitual para buscar as características necessárias dos softwares para o âmbito educacional, com base em Cantarelli (2017) de forma adaptada;

Mapa conceitual 3 - mapa conceitual na compreensão do tipo de software é mais adequado para um determinado fim;

Mapa conceitual 4 - mapa conceitual para buscar como consolidar o conteúdo programático na utilização de software de modelagem.

Para o sistema de análise qualitativo, foi desenvolvido uma forma de representação que pudesse facilitar a análise. Então, foi construído um hexágono e colocado nos seus vértices os critérios com a variação: muito fraco (0); fraco (1); médio (2); bom (3) e muito bom (4). (Figura 2).

Os softwares utilizados nesta pesquisa foram: blender; solid works; autocad map; vector work; surfer; photomodeler; zbrush; mr planet. E, visando dar base ao sistema de análise qualitativo buscou-se as potencialidades dos softwares conforme o tipo de representação gráfica e sua aplicação:

Orgânica: animais, seres humanos, personagens com feições humana, insetos, e outros, e qual tipo de área podem ser utilizadas, por exemplo: animações, games, ensino da medicina, biologia, cinema, arqueologia;

Mecânico: automóvel, peças mecânicas. Área engenharia mecânica, automação, design industrial, cinema, museologia, arqueologia;

Mobiliário: cadeira, mesa. Área arquitetura, engenharia civil. cinema, museologia, arqueologia;

Topografia: elevação do terreno, superfícies topográficas, hidrografia. Áreas: games, 
cartografia, engenharia ambiental, geografia, aquicultura, cinema, museologia, arqueologia;

Arquitetônico: planta baixas, cortes, perspectivas.

Figura 2 - Sistema de avaliação qualitativa e seus descritores

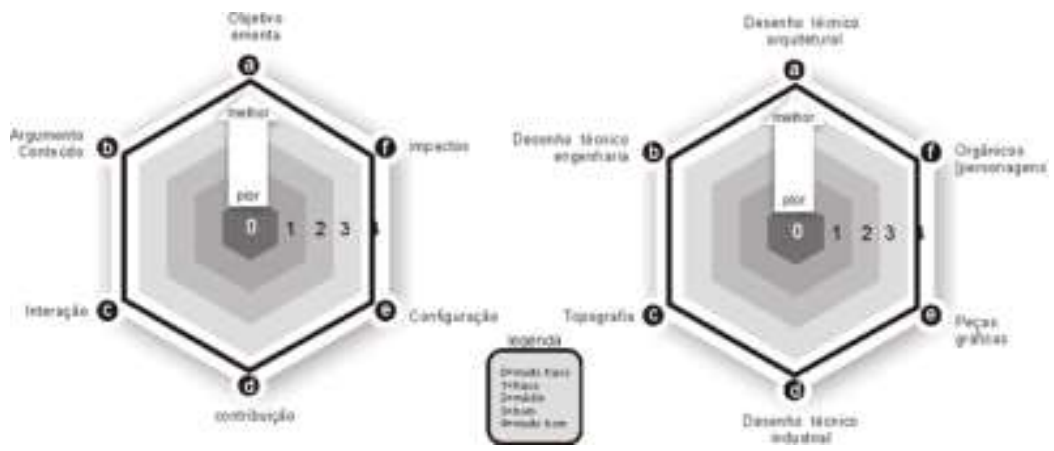

Fonte: Os autores do trabalho

A seguir será apresentado os mapas conceituais (1, 2, 3 e 4) e sua análise, como também, a potencialidade de alguns softwares e a sua relação com alguns conteúdos de disciplinas nas áreas mencionadas anteriormente. Também será apresentado a análise qualitativa realizada.

\subsection{Construção dos mapas conceituais}

\subsubsection{Mapa conceitual 1 - Determinar como proceder em atividade acadêmica}

O mapa conceitual de como proceder para determinar uma atividade acadêmica pode ser visualizado através da Figura 3. Iniciou-se a construção do mapa partindo do centro, tendo como palavra chave o procedimento, sendo este um conceito bem abrangente. As ramificações mostram as premissas do que é necessário para um bom desempenho do procedimento.

Figura 3 - Mapa conceitual de um procedimento

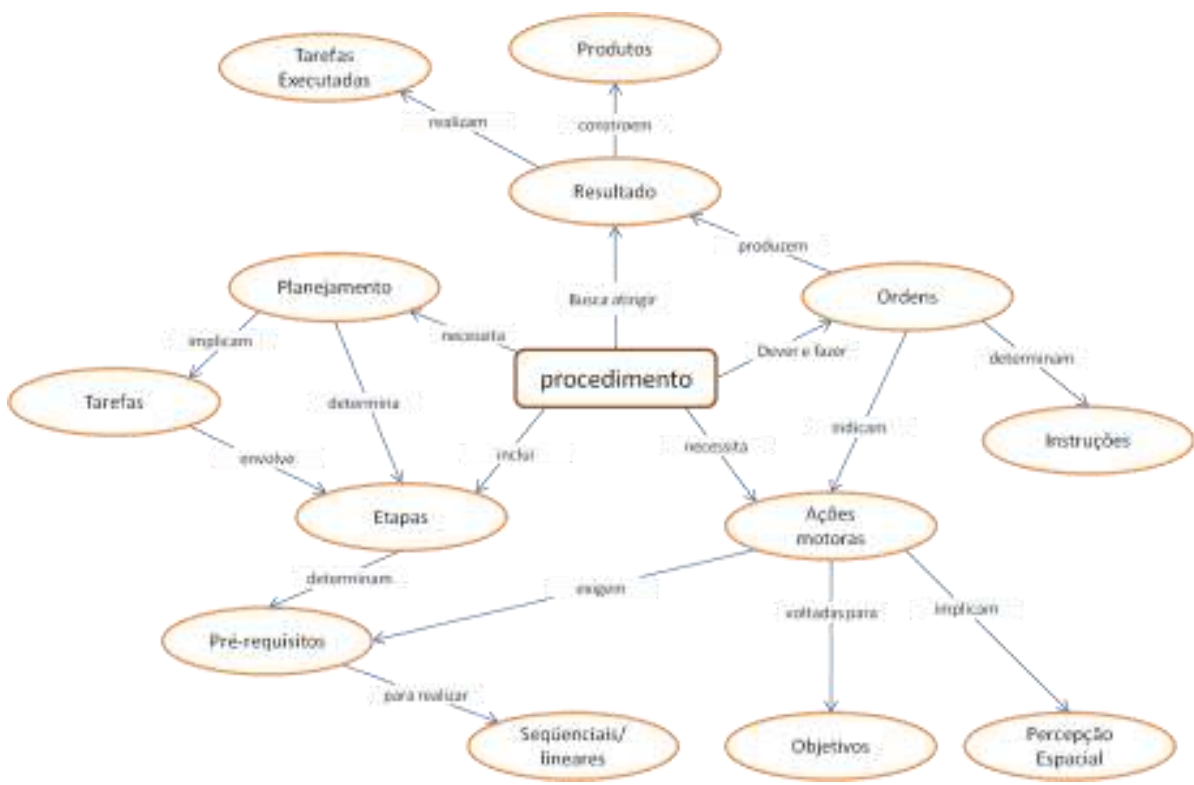

Fonte: Os autores do trabalho 


\subsubsection{Mapa conceitual 2 - Buscar as características necessárias dos softwares para o âmbito educacional, com base em Cantarelli (2017) de forma adaptada}

Segundo Cantarelli (2017) para verificar se um software possui características que assegurem o seu sucesso no âmbito educacional é necessário avaliar, a interface; o conteúdo; o grau de interatividade; a estratégia utilizada; a motivação; o controle por parte do usuário e a mídia utilizada. Partindo deste pressuposto, foi elaborado um mapa conceitual das características que um software tem que ter como requisito básico para a área acadêmica. (Figura 4).

Figura 4 - Mapa conceitual das características necessárias dos softwares

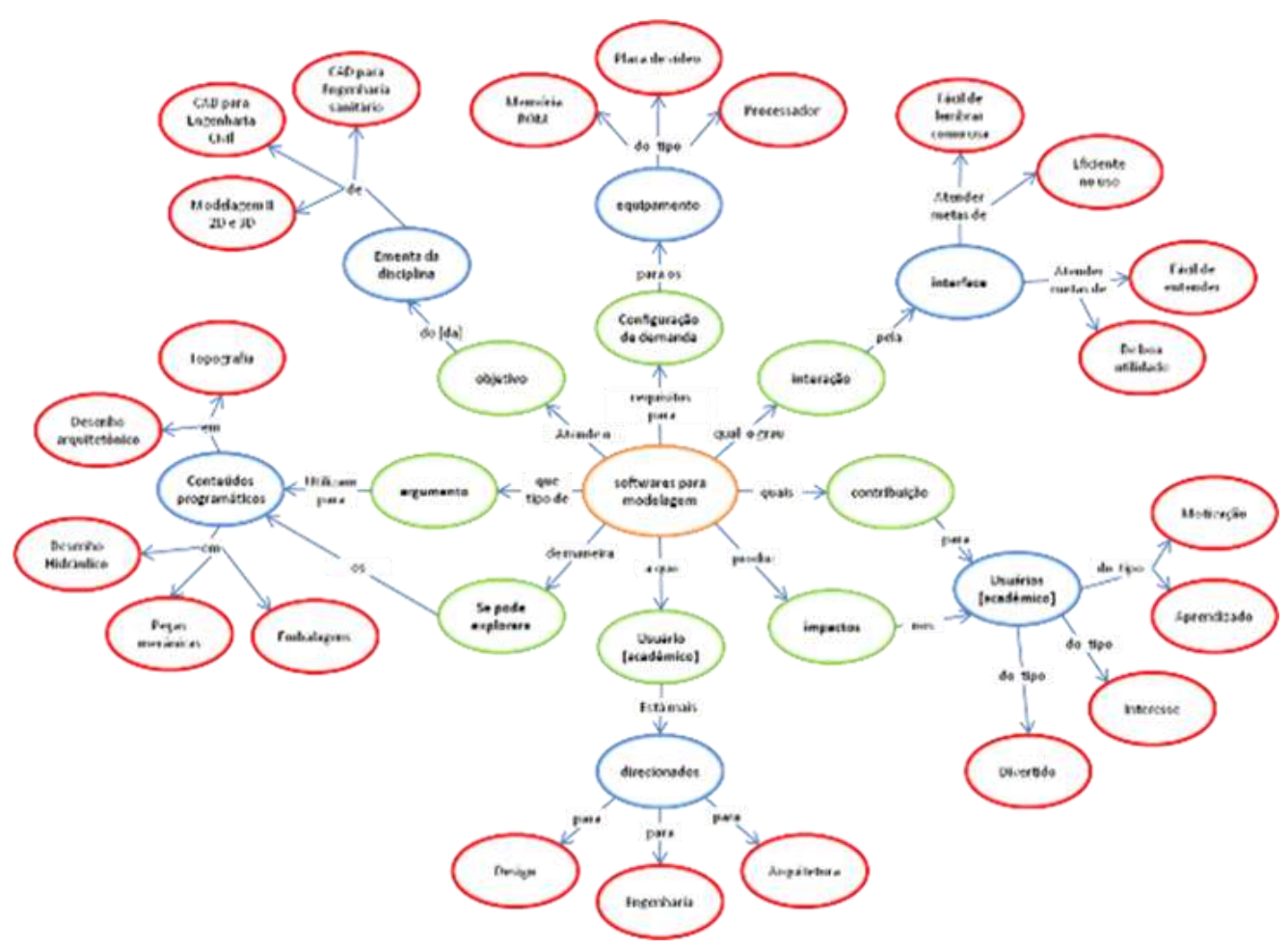

Fonte: Os autores do trabalho

\subsubsection{Mapa conceitual 3 - Compreensão do tipo de software é mais adequado para um determinado fim}

Nesta etapa foi construído um mapa conceitual para compreender o tipo de software é mais adequado para uma determinada atividade acadêmica. (Figura 5). 


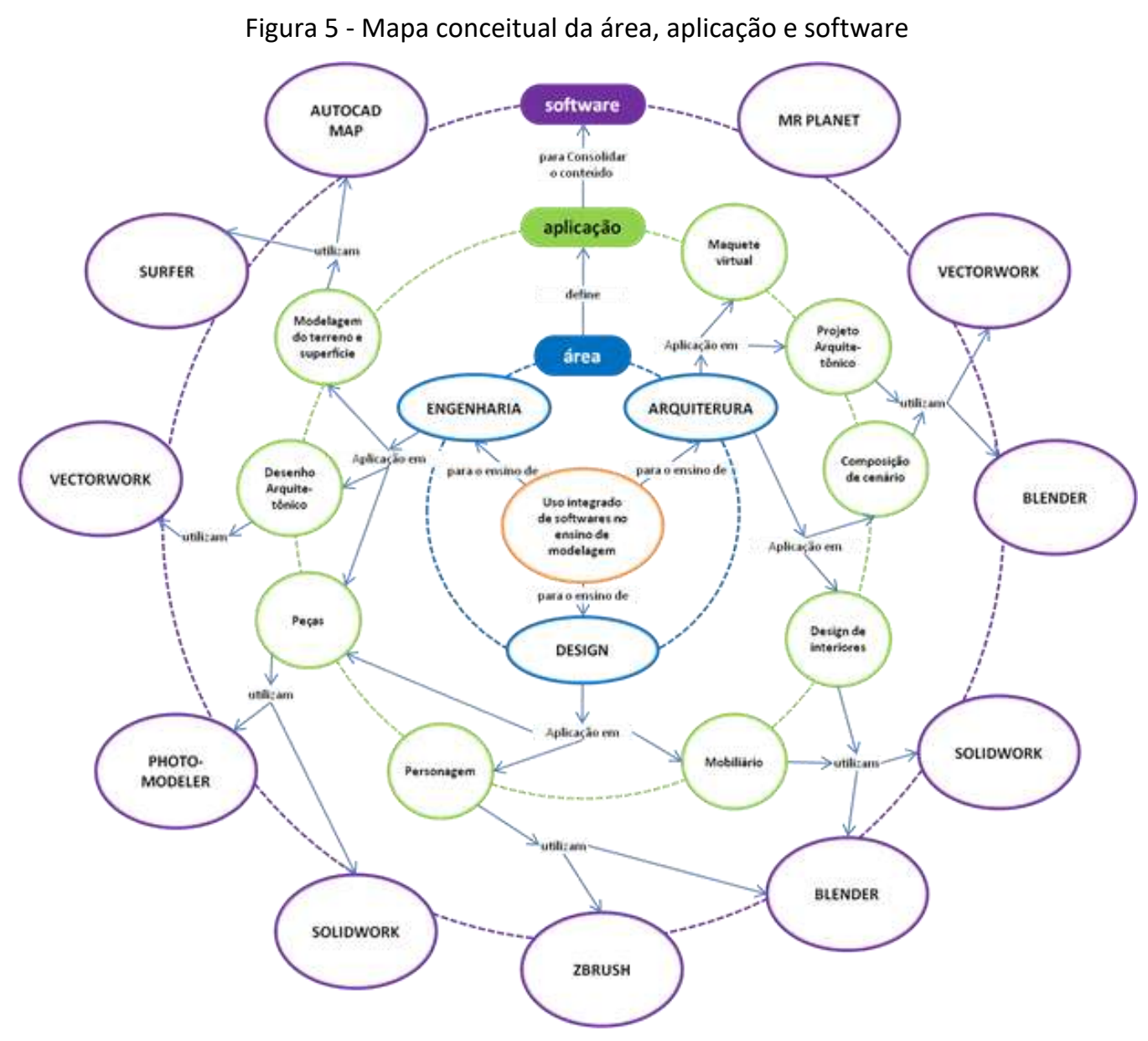

Fonte: Os autores do trabalho

\subsubsection{Mapa conceitual 4 - Consolidar o conteúdo programático na utilização de softwares de modelagem 2D e 3D}

Na finalidade de estudar como fazer a integração de vários softwares foi construído um mapa conceitual visando a consolidação de diversos conteúdos programáticos na utilização de software de modelagem, como mostra a figura 6 . 
Figura 6 - Mapa conceitual para consolidação do conteúdo e ferramenta

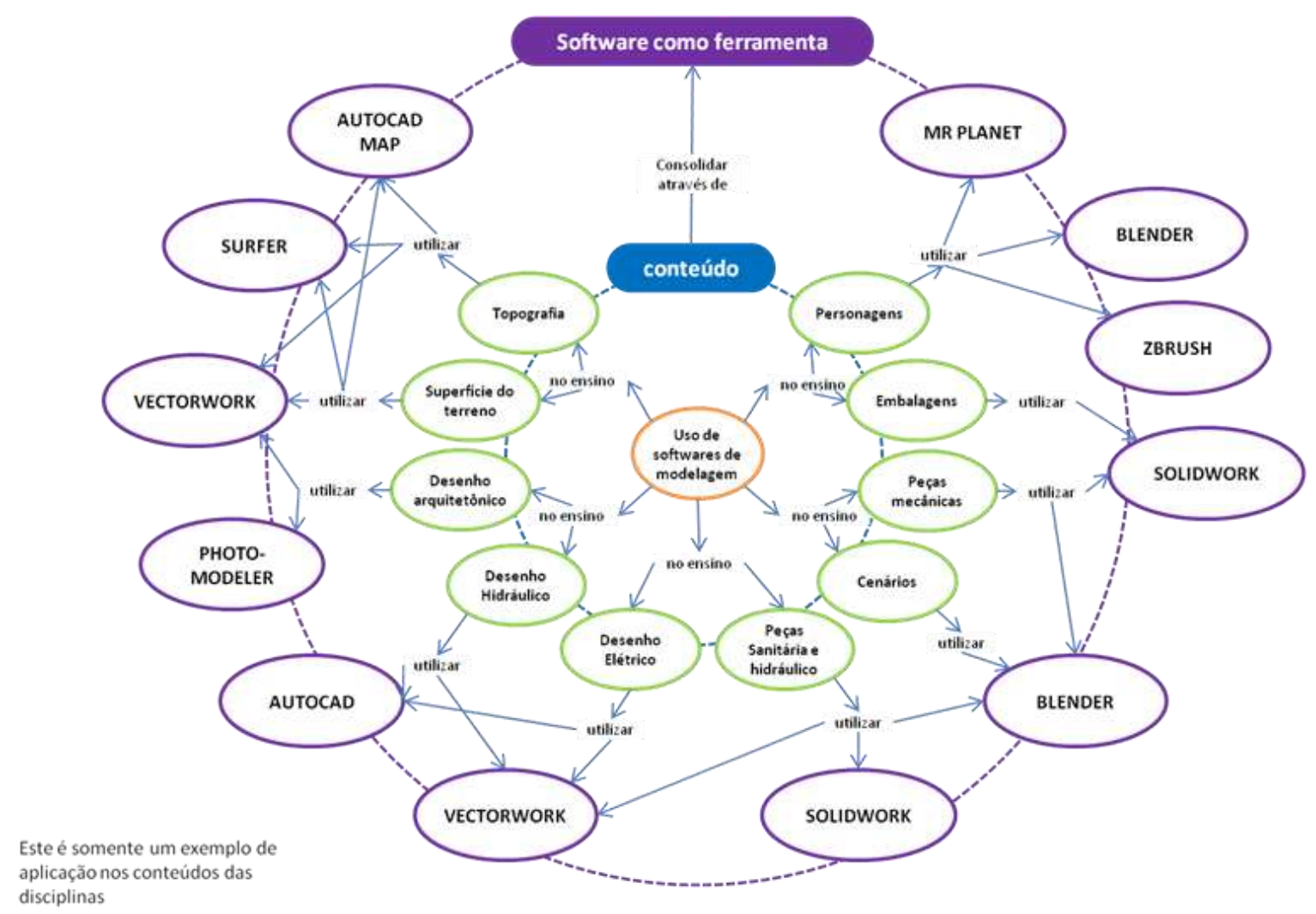

Fonte: Os autores do trabalho

\subsection{Avaliação da potencialidade dos softwares na modelagem 2D e 3D}

Alguns programas (softwares) utilizados no ensino da modelagem (2D e 3D) foram avaliados de forma qualitativa. A seguir será apresentado o processo de avaliação realizado para cada um dos softwares.

\subsubsection{Software Blender}

O Blender é um software de modelagem e animação 3D de código aberto. Além de modelagem e animação o Blender também permite a criação de jogos sem programação e a realização de pós-produção de animações com um editor de vídeo integrado (MACHADO \& MORAES, 2005). A figura 7, apresenta a avaliação qualitativa realizada para o software Blender.

Como podemos observar, analisando o gráfico, o software Blender tem uma pertinência muito grande para a área do ensino do design, principalmente em algumas áreas de estudo, como, projeto de criação e modelagem de peças orgânicas, modelagem de personagem para design de games, etc., podendo assim ser facilmente adequar aos objetivos e ementas de várias disciplinas. $\mathrm{Na}$ arquitetura isto já não é tão favorável como no design, mas isto não descarta sua utilidade nesta área, pois podemos realizar desenhos para projetos arquitetônicos, como planta baixa, fachada, etc. E também modelagem virtual 3D de ambientes. 
Figura 7 - Análise qualitativa do BLENDER
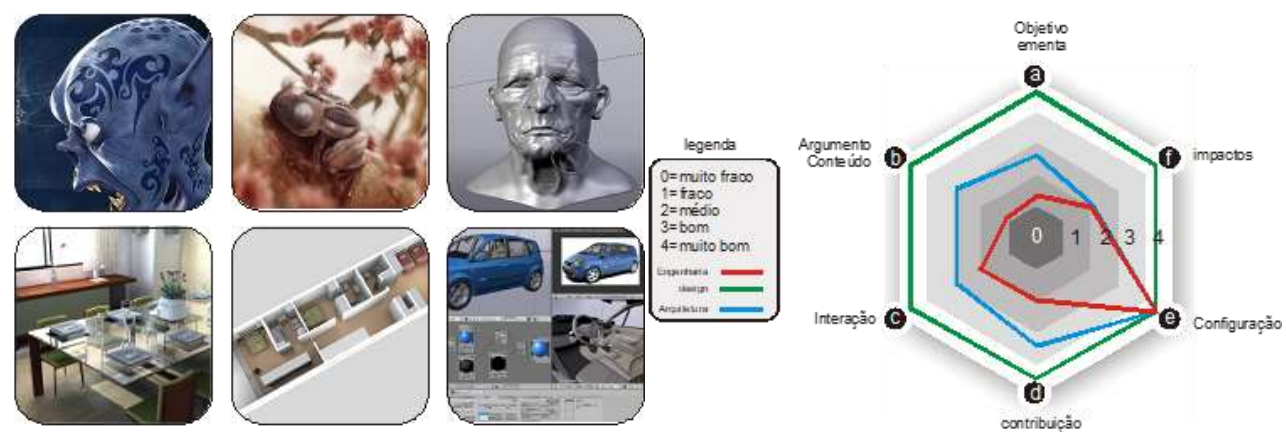

Fonte: Os autores do trabalho

\subsubsection{Software SolidWorks}

Conforme Bocchese, 2007, o SolidWorks é uma ferramenta que se baseia em computação paramétrica, criando objetos tridimensionais a partir de formas geométricas. Um dos pontos fortes, além da parametrização é a capacidade de modelagem híbrida, em que aproveitamos entidades sólidas e de superfícies para gerar modelos complexos. A figura 8 apresenta a avaliação qualitativa realizada para o software SolidWorks. O software SolidWorks, como mostra o gráfico, é muito bom para o ensino da engenharia, principalmente a mecânica e o ensino do desenho industrial.

Figura 8 - Avaliação qualitativa do SolidWorks
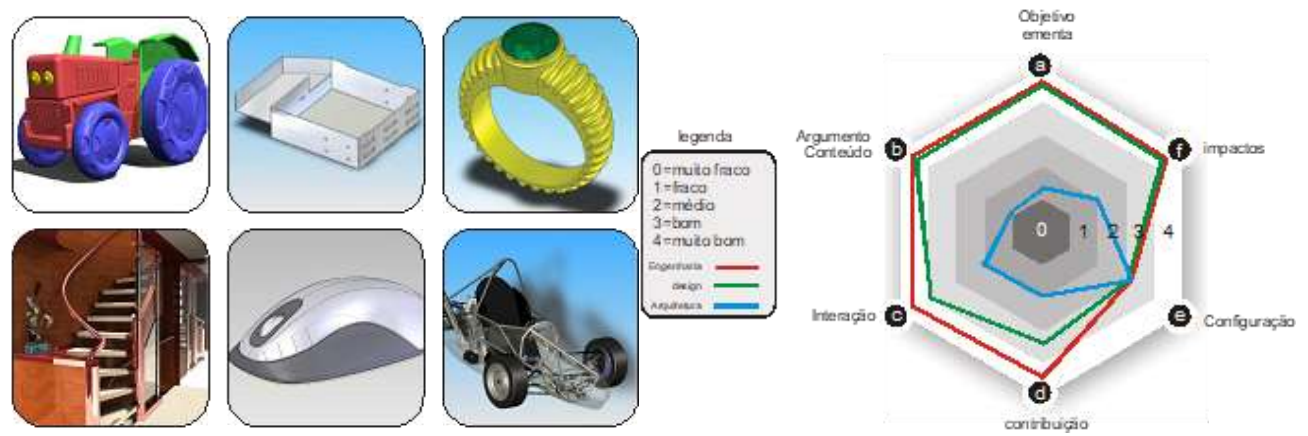

Fonte: Os autores do trabalho

\subsubsection{Software AutoCAD Map}

O software AutoCAD Map, cria mapas de precisão e a análise SIG para níveis superiores, mais produtivos. Baseia-se no AutoCAD, incluindo um conjunto abrangente de ferramentas para criação de mapas automatizadas, feitas para engenheiros, projectistas, gestores de "utilites" e qualquer pessoa que crie e proceda à manutenção de mapas. Pode-se trabalhar facilmente e com precisão, com vastos conjuntos de dados que cobrem amplas áreas geográficas. Faz a Ligação de dados alfanuméricos a características geográficas. Ele integra facilmente dados de engenharia de locais específicos com informação de grandes áreas geográficas (GÓES, 2000). A figura 9 apresenta a 
avaliação qualitativa realizada para o software AutoCAD Map.

Figura 9 - Avaliação qualitativa do AutoCAD Map
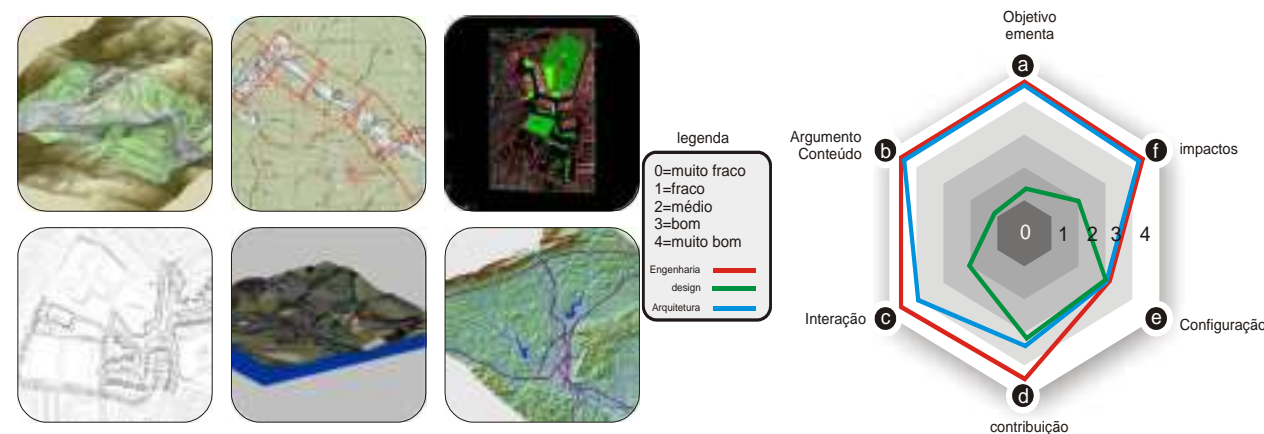

Figura 9: Os autores do trabalho

O AutoCAD Map favorece muito o ensino da engenharia principalmente a civil na área de infraestrutura com estrada, o geoprocessamento na engenharia cartográfica, no ensino da topografia ou planos cotados área da representação espacial. No design na área de games por exemplo os jogos que utilizam a representação do espaço geográfico, ou seja os princípios da cartografia.

\subsubsection{Software VectorWorks}

O VectorWorks ${ }^{\circledR}$ é um software CAD (Computer Aided Design) que foi desenvolvido há mais de treze anos pela Empresa Diehl Graphsoft Inc., e é utilizado mundialmente para o desenvolvimento de desenhos 2D e 3D nas areas de Arquitetura, Eng. Civil, Eng. Mecânica, Projetos de Exteriores e Fachads, Topografia, Eng. Elétrica, etc. (CAD TECHNOLOGY SISTEMAS, 2018).

No trabalho a 3D, pode optar por objetos paramétricos ou por modelação livre. Os objetos paramétricos, não sendo símbolos estáticos, facilitam a criação e edição de objetos comuns dos nossos projetos. A modelação livre complementa o trabalho com os elementos paramétricos (CAD TECHNOLOGY SISTEMAS, 2018). A figura 10 apresenta a avaliação qualitativa realizada para o software VectorWorks.

Figura 10 - Análise qualitativa do VectorWorks
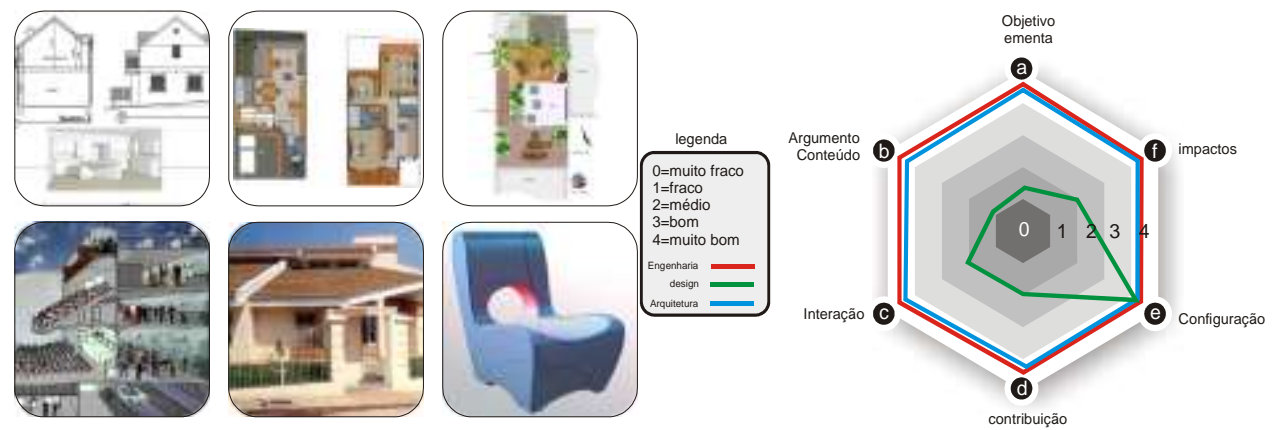

Fonte: Os autores do trabalho

O VectorWorks ${ }^{\circledR}$ é utilizado para o desenvolvimento de desenhos 2D e 3D nas áreas de Arquitetura, Eng. Civil, Eng. Mecânica, Projetos de Exteriores e Fachadas, Topografia, Eng. Elétrica, e isto está bem representado no gráfico de análise qualitativa. 


\subsubsection{Software Surfer}

O Software SURFER é um programa de mapeamento 3D que utiliza o sistema operacional Microsoft Windows. É rápido, e converte facilmente suas informações de superfícies, vetores, imagens e mapas incríveis. Todos os aspectos do mapa podem ser customizados para produzir a apresentação exata que você quer. Oferece uma renderização 3D com controle completo sobre a iluminação, sombras, posições, rotação e ângulos. Como também, mapas rasterizados e vetorizados, de imagem, post, etc. Combina grids adjacentes e arquivos DEM (Modelagem Digital de Elevação) em um único GRD para produzir um mapa. A figura 11 apresenta a avaliação qualitativa realizada para o software Surfer.

Figura 11 - Análise qualitativa do Surfer
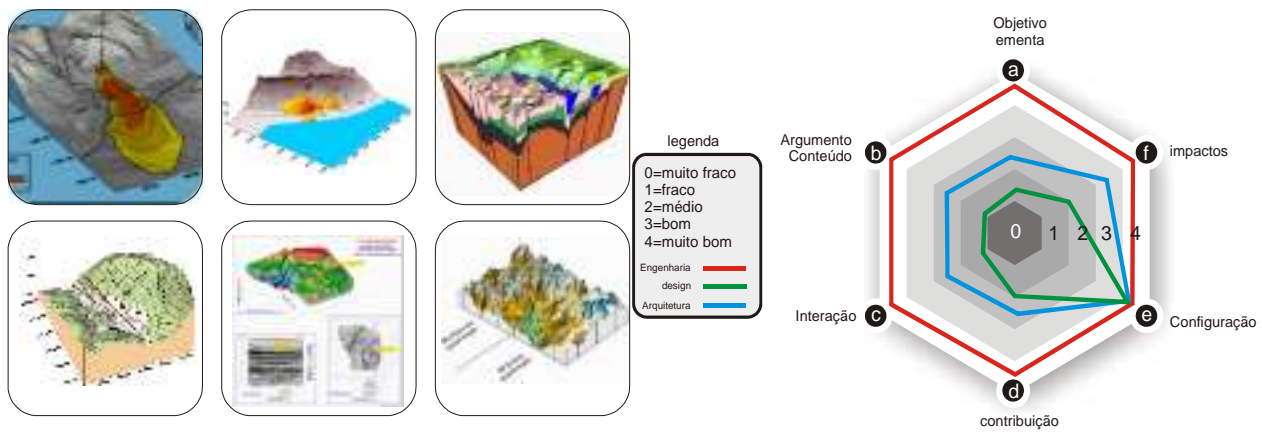

Fonte: Os autores do trabalho

Tanto o Software Surfer como o AutoCAD Map, favorecem muito o ensino da engenharia principalmente a civil sanitária e ambiental e isto está bem representada no gráfico.

\subsubsection{Software Photomodeler}

O photomodeler é um software que tem ganhou diversos prêmios e é utilizado por profissionais em todo o mundo para gerar modelos 3D e fazer medições 3D, a partir de fotografias 2D. A precisão de uma medição final com o software photomodeler depende de alguns: resolução e número de fotografias, ângulos entres as fotografias, número de pontos referenciados e qualidade da câmara. A precisão está entre 1/200 para fotografias de baixa resolução (para um objeto de 2 metros a precisão será de $1 \mathrm{~cm}$ ) e 1/15 000 para fotografias de alta resolução (para um objeto de 2 metros a precisão será de $0,08 \mathrm{~mm}$ ). As câmaras podem ser; Câmaras de filmar (as imagens podem ser digitalizadas com um scanner de negativos), Câmaras digitais e Câmaras de vídeo. A figura 12 apresenta a avaliação qualitativa realizada para o software Photomodeler.

Figura 12 - Análise qualitativa do photomodeler
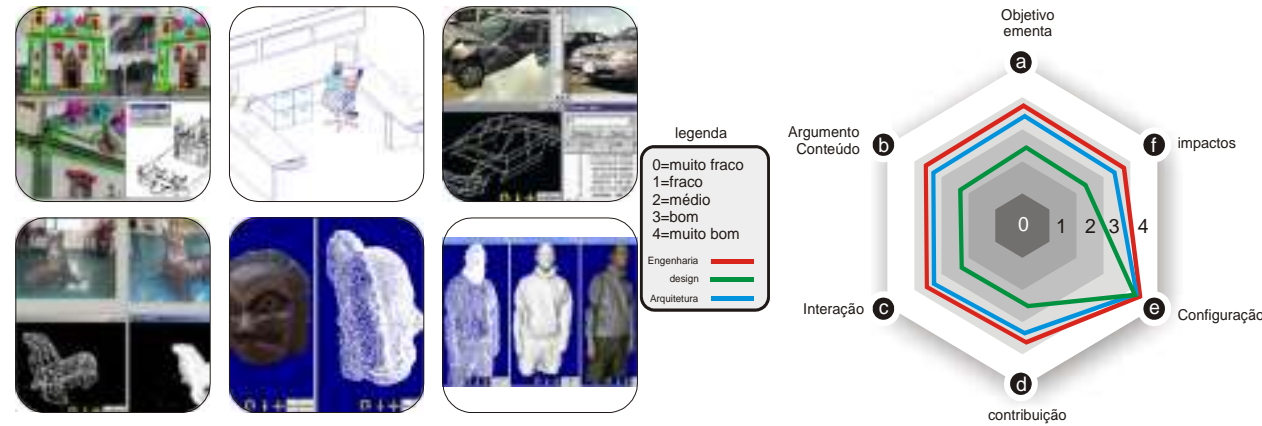

Fonte: Os autores do trabalho 
O photomodeler por ser de fácil utilização e não é necessário qualquer treino especial, tem com premissa no ensino a compreensão da percepção espacial, onde se trabalha com modelos reais passando para o virtual, possibilitando também a orientação automática da câmara fotográfica introduzindo assim para o aluno outros equipamentos para motivação de aula, na avaliação mostra uma posição bem favorável para todas as áreas no ensino da representação visual.

\subsubsection{Software ZBrush}

O ZBrush é um software de modelagem 3D usado em filmes, animações, etc. É um software de escultura com características únicas, tem sido integrado no fluxo de trabalho de grandes estúdios, tanto para a produção de filmes como para a indústria de games, além de ser excelente na criação e desenvolvimento de ilustrações, design de criaturas, e parceiro fundamental no processo de criação de mapas de relevos e detalhes para o posterior render em softwares 3D. A figura 13 apresenta a avaliação qualitativa realizada para o software

Figura 13 - Análise qualitativa do ZBrush
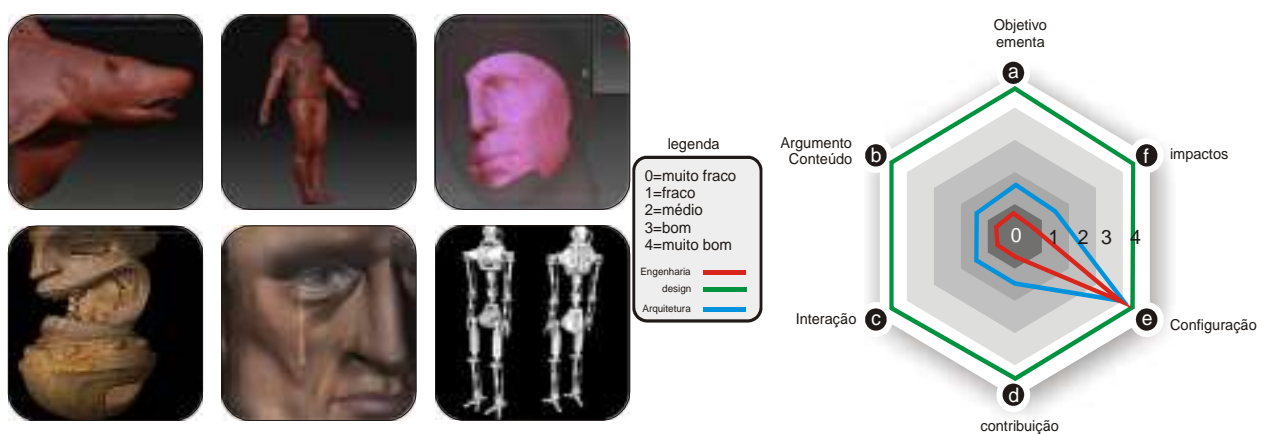

Fonte: Os autores do trabalho

Como podemos ver o ZBRUSH é muito bom para modelagem de peças orgânicas, tendo um bom potencial para a área do design principalmente na criação de personagens.

\subsubsection{Software MR planet}

O MR Planet é um software que possui uma interface simples para os usuários. Estabelece ligação com outros softwares como o AutoCad, 3D Studio Max, Blender, através de padrões variados de realidade aumentada - Augmented Reality (AR). Pois, esta ferramenta permite para modificar a escala para girar o modelo e para traduzi-lo em relação ao padrão com um simples menu de opções. Além disso, esses modelos também podem conter animações que será capaz de reproduzir a partir da aplicação. A figura 14 apresenta a avaliação qualitativa realizada para o software MR Planet. 
Figura 14 - Análise qualitativa do MR planet
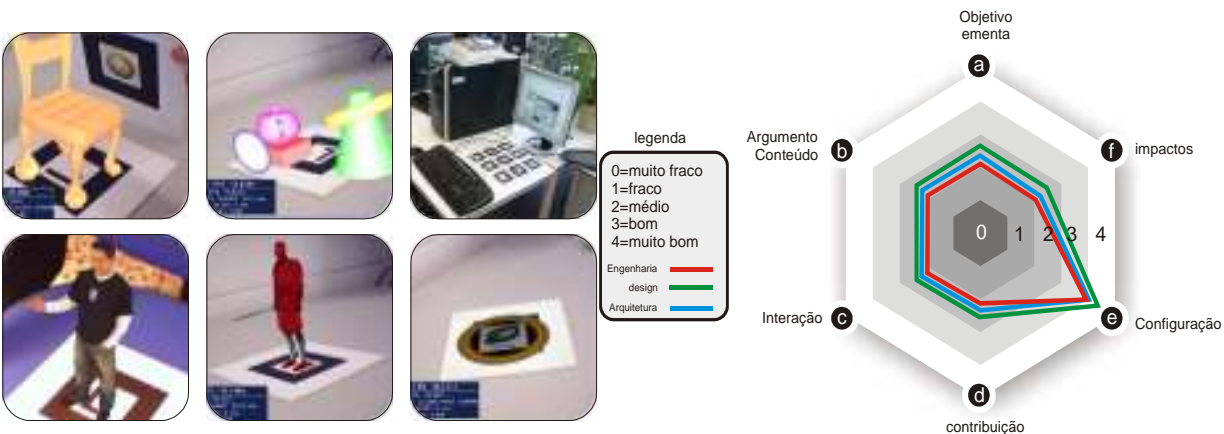

Fonte: Os autores do trabalho

O MR Planet é um software indicado para visualização, mas tem suas potencialidades porque é possível ver em seus modelos as animações, podendo integrar com instrução mais modelos virtuais, dando motivação para o aluno na compreensão da representação espacial.

\section{Resultado}

Após realizar a análise local de cada software, foi possível ter uma visão global das potencialidades dos softwares frente as diferentes disciplinas que o utilizam para modelagem 2D e 3D, como mostra a figura 15 . Verifica-se que todos eles, dentro da particularidade de cada software, uns mais voltados a modelagem orgânica e outros mais a parametrização é a capacidade de modelagem híbrida, atendem aos diversos conteúdos programáticos e determinada atividade acadêmica, na área de modelagem 2D e 3D, dos cursos de arquitetura, engenharia e design.

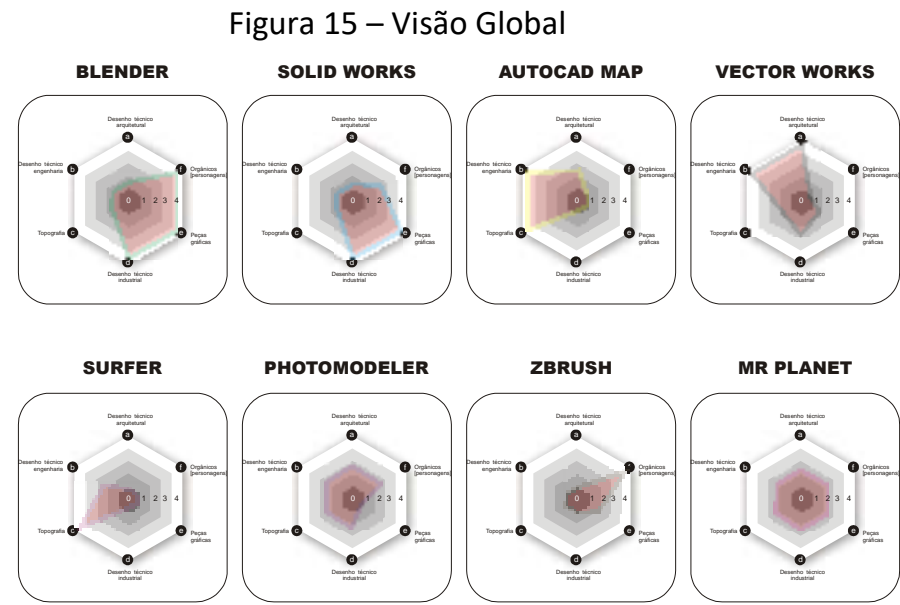

Fonte: Os autores do trabalho

\section{Conclusão}

Concluímos que as ferramentas utilizadas neste trabalho tornaram possível a análise da potencialidade de cada software para determinada área e conteúdo programático específico. Os mapas conceituais ajudaram no planejamento e análise do conteúdo, bem como, na reflexão de qual software é mais pertinente para determinado conteúdo programático.

A análise realizada apoiou a decisão no que se refere a potencialidade de cada software para 
cada conteúdo programático. Este estudo pode ser ampliado para outras áreas e disciplinas, o que certamente demandará pré-seleção das ferramentas específicas disponíveis, bem como uma revisão constante frente a novas versões e atribuições de funcionalidades.

\section{Referências}

AUSUBEL, D.P. Educational Psychology: A cognitive View. NY: Holt, Rinechart and Winston, 1968.

BARCELOS, G. T. Inovação no sistema de ensino: o uso pedagógico das tecnologias de informação e comunicação nas licencenciaturas em matemática da região sudeste. Campos dos goytacazes RJ. junho - 2004. Dissertação de mestrado. Universidade Estadual Norte Fluminense (UENF). 217pg.

BASTOS, F. P.; FIM, A. T.; MAZZARDO, M. D. Ambientes virtuais de ensino-aprendizagem: os desafios dos novos espaços de ensinar e aprender e suas implicações no contexto escolar. Novas Tecnologias na Educação/CINTED-UFRGS. V. 3 № 1, Maio, 2005.

BAX, M. P.; SOUZA, R. R. Uma Proposta de Uso de Agentes e Mapas Conceituais para Representação de Conhecimentos Altamente Contextualizados. Simpósio Internacional de Gestão do Conhecimento, Curitiba, PR. 2001.

BOCCHESE, C. Solidworks 2007: Projeto e desenvolvimento. São Paulo: Érica, 2007

BRAGA, M. Realidade Virtual e Educação. Revista de biologia e ciências da terra. Vol. 1, N. 1, 2001.

CAD TECHNOLOGY SISTEMAS, 2018 (http://www.cadtec.com.br/new/home.php)

CANTARELLI, E. M. P. Software educacional, Frederico Westphalen, 2017

GIRAFFA, L.M.M. Uma arquitetura de tutor utilizando estados mentais. Porto Alegre: CPGCC/UFRGS, 1999. Tese de Doutorado.

GÓES, K. Explorando as Ferramentas de mapeamento do AutoCAD Map. Ciência Moderna, 2000. GOULART, R.R.V; GIRAFFA, L.M.M. Auxiliando o tutor na gerência das informações do ambiente e dos alunos. In: SEMINÁRIOS DE ANDAMENTO 2001, Porto Alegre. Anais: PUCRS/PPGCC, 2001.

GUERRA, W. A. Mapas conceituais como instrumentos para investigar a estrutura cognitiva em Física. Dissertação de Mestrado. Porto Alegre, 1983.

LEAKE, J.M.; BORGERSONN, J.L. Manual de Desenho Técnico para Engenharia: Desenho, modelagem e visualização. Rio de Janeiro: LTC. 2aㅡ ed. 2015.

MACHADO, L.S. e Moraes, R.M. Cenários 3D Interativos com Software Livre, Revista de Informática Teórica e Aplicada. Vol. 12, No. 2, pp. 91-112, 2005.

MERCADO, L. P. L. Formação docente e novas tecnologias. Universidade Federal de Alagoas - Brasil. IV Congresso RIBIE, Brasília 1998.

MORAN, José Manuel. Informática na Educação: Teoria \& Prática. Porto Alegre, vol. 3, n., 2000.

NOVAK, J. D. Retorno a Clarificar con Mapas Conceptuales. Encuentro Internacional sobre el Aprendizaje Significativo. Actas. Universidad de Burgos, p. 67-68, 1997.

ROCHA, R.; CAMPOS, G. Avaliação de qualidade de software educacional. Brasília, n. 57, 1993.

SILVA, C.M.C. Novas tecnologias na educação: o professor como mediador no processo educativo. Florianópolis - Brasil, 2000. Dissertação de Mestrado. Engenharia de Produção, UFSC. 